\title{
Application of a Novel PVA-based Proton Exchange Membrane Modified by Reactive Black KN-B for Low-temperature Fuel Cells
}

\author{
Tianchi Zhou ${ }^{1,2, *}$, Yang $\mathrm{Li}^{2}$, Wei Wang ${ }^{2}$, Lanhua He ${ }^{2}$, Lu Cai ${ }^{2}$, Chunmei Zeng ${ }^{1}$ \\ ${ }^{1}$ Jiangsu R\&D Center of the Ecological Dyes and Chemicals, Yancheng Polytechnic College, 285 \\ Jie'fang South Road, Yancheng 224005, China \\ ${ }^{2}$ College of Textile and Garment, YanCheng Institute of Technology, 1 Xi'wang middle Road, \\ Yancheng 224051, China \\ *E-mail: 120413181@qq.com
}

doi: 10.20964/2019.09.16

Received: 1 May 2019 / Accepted: 18 June 2019 / Published: 31 July 2019

\begin{abstract}
A novel proton-conducting membrane using poly(vinyl alcohol) (PVA) as matrix and Reactive Black $\mathrm{KN}-\mathrm{B}$ as conductive component was fabricated through a solution casting method combined with a colour-fixing process. Fourier transform infrared (FT-IR) spectroscopy, X-ray photoelectron spectroscopy (XPS), X-ray diffraction (XRD) analysis and scanning electron microscopy (SEM) showed that KN-B dye was successfully grafted onto the PVA macromolecules and that the internal structure of the membrane became denser and rougher due to cross-linking of the colour-fixing agent DE. The $\mathrm{H}^{+}$ conductivities of the synthesized membranes were evaluated using alternating current (AC) impedance measurements. The results indicated that the $\mathrm{H}^{+}$conductivity of PVA/KN-B membranes could reach $0.124 \mathrm{~S} \mathrm{~cm}^{-1}$ at $20^{\circ} \mathrm{C}$. Thermal analysis and the investigation of mechanical properties, water uptake and swelling behaviour also showed that the membranes possessed excellent physical stability. When immersed in a solution of $30 \mathrm{wt} . \%$ hydrogen peroxide, PVA/KN-B/DE membranes showed excellent oxidative stability and their weights remained at approximately $72.8 \mathrm{wt} . \%$ of the original sample weight within $168 \mathrm{~h}$ at room temperature.
\end{abstract}

Keywords: Membrane; Proton conductivity; Vinyl-sulfone reactive dyes; Fuel cell; Oxidative stability

\section{$\underline{\text { FULL TEXT }}$}

(C) 2019 The Authors. Published by ESG (www.electrochemsci.org). This article is an open access article distributed under the terms and conditions of the Creative Commons Attribution license (http://creativecommons.org/licenses/by/4.0/). 